\section{Der wimmernde Wicht und der Rabbi von Porto}

H. Vogt

Im Spätsommer des Jahres 2000 geschah es im ukrainischen Lviv, dass eine Frau ihr Kind ohne die Hilfe einer Hebamme zur Welt brachte. Sie befand sich in einer so verzweifelten Lage, dass es ihr unmöglich schien, neben ihrem eigenen Hunger noch den eines kleinen Schreihalses zu stillen.

Sie durchtrennte die Nabelschnur, wickelte das Kind notdürftig in eine Windel, gab ihm die Brust, packte es in eine zerschlissene Reisetasche und legte es in der Nähe eines Spitals vor einen Hauseingang.

Als zwei Krankenschwestern einer gynäkologischen Abteilung nach der Nachtschicht ihr Krankenhaus verliessen, bemerkten sie beim Haus gegenüber eine Menschenansammlung. Da lag ein Gepäckstück am Boden. Neugierig aber distanziert standen die Leute darum herum. «Eine Bombe? In Russland ist das jetzt gang und gäbe.» "Da bewegt sich ja etwas. Es muss eine Katze sein, oder sonst ein Tier.» "Es wimmert. Das tönt ganz nach Katze.» Die Schwestern brauchten kein Stethoskop um die Diagnose zu stellen. Sie packten zu und brachten das Bündel auf die Geburtenabteilung. Dort nahm sich die Säuglingsschwester des Findlings an, säuberte und umsorgte das Neugeborene. Das Kind wurde bald munter und lebensfrisch und wog 3100 g. Ein Mädchen.

\section{Abbildung 1}

"Wenn Kinder nicht im Kohl, sondern im Container gefunden werden.»

"Das Aussetzen von Kindern wird häufiger, Adoptionen werden immer seltener.» Der Zeitungsbericht über Vera Ihorievna Rapoport.

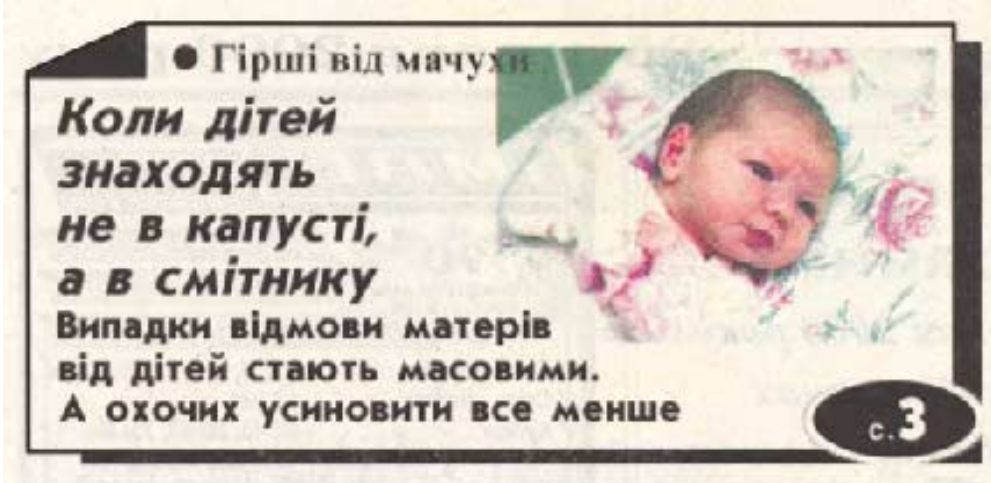

Korrespondenz:

Heiner Vogt

Brüggetli

CH-3704 Krattigen

E-mail: heiner@vogt.org
Damit war es nun nicht mehr in Gefahr, auf einer Müllhalde zu enden. Aber als vollwertiges Mitglied der menschlichen Gesellschaft brauchte es einen Namen, genauer zwei, im dortigen Sprachgebiet sogar drei.

Wir wollen die Schwester bei ihrer Namenssuche nicht stören und wenden uns kurz dem Spital zu, das die Mutter vermutlich in weiser Voraussicht ihrem Kind zugedacht hatte.

Der leicht orientalisch anmutende, langgestreckte Bau wurde vor gut hundert Jahren von einem privaten Wohltäter erbaut, mit modernen Einrichtungen versehen und der jüdischen Gemeinde von Lemberg geschenkt. Damals war ein Drittel der Bevölkerung der Hauptstadt des österreichischen Kronlandes Galizien-Lodomerien jüdisch.

Der Name Rapoport-Krankenhaus sollte an eine alteingesessene Lemberger Familie erinnern, die sich im Laufe der Jahrhunderte verschiedentlich um die jüdische Sache verdient gemacht hatte. Er geht zurück auf einen Rabbi von Porto, der während der Inquisition aus Portugal fliehen musste. Seine Nachkommen gelangten nach Italien und liessen sich schliesslich in Lemberg nieder.

Das Spital machte die wechselvolle Geschichte der Stadt mit, für deren kranke Einwohner es errichtet war. Nach dem ersten Weltkrieg wurde das österreichische Lemberg zum polnischen Lwow. Als die Nazis 1941 einmarschierten, wurde das Krankenhaus seinem Zweck entfremdet, blieb aber unbeschädigt. Drei Jahre später kamen die Russen, das frühere Galizien wurde dem sowjetischen Territorium einverleibt, und die Stadt hiess fortan Lvov. Aus dem Rapoport-Spital wurde eine staatliche Klinik.

Als die Ukraine am 24. August 1991 ihre Unabhängigkeit erklärte, änderte der Name nochmals und wurde zu Lviv. Das Rapoport-Spital behielt seine ursprüngliche Bezeichnung und seine Aufgabe.

1904 erhielt das Krankenhaus Besuch von einer der berühmtesten Patientinnen der Medizingeschichte und einer der profiliertesten Feministinnen Deutschlands. Die Gründerin und Vorsitzende des jüdischen Frauenbundes in Frankfurt hatte einen bescheidenen Wunsch: Es sei «wenigstens eine gebildete Frau, eine geschulte Kraft» in diesem Krankenhaus einzustellen. Die orthodoxen jüdischen Kreise waren ausser sich vor Empörung: Es bedeutete für sie einen Verrat am Judentum, wenn eine junge Frau den Beruf einer Krankenschwester erlernte.

Frau Pappenheim - so hiess der Gast aus Frankfurt - hatte den Frauenbund gegründet, um sich dem "weissen Sklavenhandel" entgegenzustellen. Der wurde betrieben von Mädchenhändlern, die junge Jüdinnen aus Osteuropa in den Westen lockten, um sie in alle Welt, wenn nötig bis Südamerika, an Bordelle zu verschachern.

Der Not gehorchend erweiterte der Bund bald einmal seinen Tätigkeitsbereich. Im Heim für ledige Mütter in Neu-Isenburg bei Frankfurt fanden Frauen eine Zuflucht, während sie lernten, für sich selber und ihre Kinder zu sorgen, bis eine geeignete Stelle gefunden war, so dass sie sich über Wasser halten konnten. 


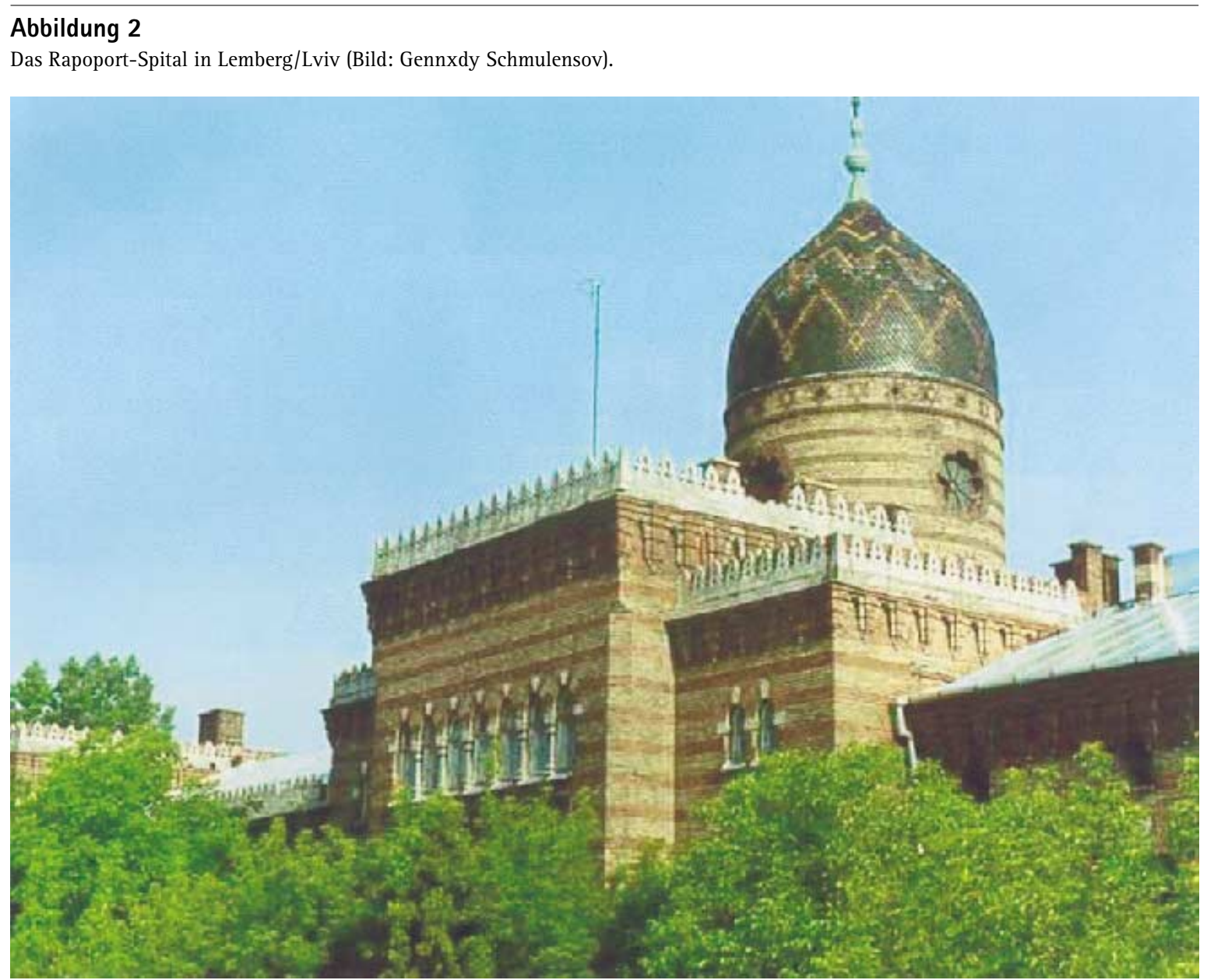

Bertha Pappenheim war nach dem Tod ihres Vaters seelisch schwer erkrankt. In ihrer Geburtsstadt Wien wurde sie vom Arzt Josef Breuer behandelt, dem väterlichen Freund des damals noch wenig bekannten Sigmund Freud. Die beiden publizierten den Bericht über diese analytische Therapie als eine ihrer ersten Fallstudien unter dem Titel "Anna 0".

Inzwischen haben sich Hebammen und Säuglingsschwestern über den Namen ihre Gedanken gemacht. Allen leuchtet ein, dass der Name des Spitals, in dem das Kind erst definitiv zum Leben kam, der geeignetste wäre. Den ersten Vornamen erhält es von der Schwester, welche die erste Hilfe leistete. Den zweiten vom Ärzteteam. Vera Ihorievna Rapoport - so heisst die nun vollwertige Erdenbürgerin. Jahrhunderte nach seinem Tod und zwei Menschenalter nach der Endlösung der Judenfrage in Galizien hat der Rabbi von Porto ein Kind geschenkt bekommen.

Die Ärztepartnerschaft «Bär und Leu» (Bern/Lemberg) hat sich und ihr Projekt, den Mittagstisch für bedürftige Kinder, in Heft 34/2000 der Schweizerischen Ärztezeitung vorgestellt. Inzwischen hat die Marienvereinigung Küche und Speiseraum eingerichtet, und die Kinder erhalten jeden Tag eine warme Mahlzeit. Der Betrag von Fr. 1.- genügt für ein Essen, bei dem jedes Kind satt werden kann. Für das neue Jahr fehlen uns noch einige Partnerschaften. Wer möchte, kann sich genauere Informationen beim Autor bestellen. 